\title{
VOS in Greek ${ }^{*}$
}

\author{
Evi Sifaki \\ University of Roehampton \\ e.sifaki@roehampton.ac.uk
}

\begin{abstract}
This paper looks into the VOS order in Greek and its focusing patterns. Evidence from main and embedded VOS reveals that embedded VOS is more restricted in its focusing possibilities. If the focus effects of main and embedded VOS differ, then we cannot advocate fixed Focus Projections in the syntactic architecture like the cartographic approaches do. Chomsky (2007; 2008) divides features in two types; the probe-agreement ones which trigger obligatory movement and the $\mathrm{E}($ dge $) \mathrm{F}$ (eature) which facilitates movement and yields information structure effects at the Interface. In effect, Greek VOS is viewed as the result of a single derivation in which movement is induced for the satisfaction of an EF. The focus effects that are present in VOS are not assigned in Syntax, but at the Interface. The claim here is that Syntax is 'blind' to information structure properties. Yet, in order to explain how one single derivation maps out to two distinct focusing possibilities, we employ the notions of accessibility and saliency, as these are discussed in Slioussar (2007) and developed in Kechagias (2010). Roughly, accessibility corresponds to topics and saliency to foci. In Greek VOS, saliency tends to mark constituents to the right of the verb (i.e. object, or manner adverb).
\end{abstract}

\section{Keywords}

VOS; focus; Edge Feature; Interface; accessibility; saliency

\section{Introductory Remarks}

The aim of this paper is to investigate the properties of the Greek VOS order and try to account for them in a comprehensive manner. VOS displays different focusing patterns which have triggered a number of analyses in the literature. These analyses (cf. Georgiafentis 2001; 2003, Philippaki-Warburton 2001, etc.)

\footnotetext{
"Various people are mentioned in different places in this paper for their individual contributions. I am grateful to them. I have benefited greatly from discussions with Ioanna Sitaridou at various times. Akis Kechagias entrusted his Thesis to me before he had the time to implement the final corrections. I am indebted to both of them as well as to Marc Richards who took the time to answer all my questions on recent Chomskyan advances. I also wish to thank the two anonymous reviewers for their constructive criticism. Needless to say that all interpretations and errors are entirely my own.
} 
tend to either generate Focus Projections in the syntactic derivation in the spirit of the cartographic approaches (see Belletti 2001; 2004) or view the different focusing patterns as the result of prosodic movement (cf. Zubizarreta 1998). As a result, all these accounts assign a distinct derivation to each focusing possibility of Greek VOS.

In particular, the present paper discusses VOS in main and subordinate clauses. No account has looked at embedded VOS before. Embedded VOS has more restricted focusing possibilities than main VOS. If focus cannot mark the same constituents in the main and embedded clausal architecture, then we need to dispense with the generation of fixed Focus Projections. To support this further data is brought forward from Romance languages (cf. Costa and Kula 2008). The evidence shows that syntax is blind to focus assignment. However, if focus is not a syntactic primitive, how can we explain the different focusing patterns evident in VOS?

Given the null subject nature of Greek and the subject-inverted word orders available in the language, the discussion moves to how $\mathrm{E}$ (xtended) $\mathrm{P}$ (rojection) $\mathrm{P}($ rinciple) satisfaction on SpecTP is achieved. EPP on $\mathrm{T}$ in its original implementation expresses the requirement that a subject appears on SpecTP. Given the lack of overt subjects and the verb initial orders in Greek, in which the subject does not occupy the SpecTP, Alexiadou and Anagnostopoulou (1998) argue that it is the verbal morphology in Greek and its nominal character that may delete the EPP feature of T through V-T movement. Greek impersonal constructions and the defective nature of the verb in these cases, demonstrate that $\mathrm{V}-\mathrm{T}$ movement cannot always delete the EPP of T. Furthermore, evidence from various languages that cannot tolerate a V1 order, but require an XP clauseinitially, points to two conclusions: (a) that EPP on T may be a more general feature satisfied by elements other than the subject, and (b) that EPP satisfaction may trigger information structure effects, given that these XPs that satisfy the EPP tend to be topics.

Relying on Chomsky (2007; 2008), Greek VOS is analysed as the result of one single derivation in which the verb moves to $\mathrm{T}$ to satisfy the agreement features and the object moves to the outer SpecvP to satisfy an E(dge) F(eature). Object movement for EF satisfaction in VOS may also have information structure effects (i.e. focus assignment), but these properties are assigned at the Interface. In order to account for the fact that focus may mark different constituents in VOS, we explore assumptions entertained in Slioussar (2007). She argues that the notions of accessibility and saliency existent in the grammar are relevant for the interpretation of lexical elements as topic and focus, respectively. Lexical elements receive an interpretation as topics and foci at the Interface. The last section attempts to show how Slioussar's model for Russian could potentially work for Greek VOS. The only difference between Russian and 
Greek VOS is directionality. She assumes that the most accessible elements appear higher up in the derivation, whereas the salient elements are the most deeply embedded. This prediction is not borne out for Greek. If Syntax sends off material to the Interface in the form of phases, then focus seems to favour elements to the right of the verb and as a result the most salient element in Greek VOS is located at the edge of the vP phase (cf. section 5.1.2).

The paper is structured as follows. Section 2 outlines the possible word orders in Greek. In particular, section 2.1 discusses the focusing possibilities in main VOS and draws a distinction between new information focus and contrastive focus. Section 2.2 investigates the position of manner adverbs in main VOS. Manner adverbs seem to be tolerated only to the right of the verb and whenever present they are the only elements to receive the focus. In section 2.3 the focusing patterns of otan, afou, an, na and oti embedded clauses are discussed. Embedded VOS is more restricted in focus assignment than main VOS. As a result embedded VOS provides evidence against the generation of fixed Focus Projections. Section 3 offers an evaluation of previous accounts of Greek VOS, which either generate Focus Projections or permit prosodically driven movement in the derivation. Section 3.1 presents further evidence from Romance languages against the generation of Focus Projections. Given that Greek is a N(ull) $\mathrm{S}$ (ubject) $\mathrm{L}$ (anguage) and a subject or the verbal morphology cannot always satisfy the EPP, section 4 moves to investigate EPP satisfaction on T. In section 4.1 it is empirically shown that EPP is a more general feature than is widely assumed in the literature, it may also bring about information structure effects. In section 4.2 recent minimalist advances come to support the empirical data of section 4.1. According to Chomsky (2007; 2008), EF (previously EPP) is a feature that facilitates movement and is available in every projection. On the basis of assumptions in 4.2, section 5 derives Greek VOS and VadvOS and concludes that Syntax is oblivious to different focus assignment patterns in these orders, hence explains why these different focus assignment patterns have one and only one representation. However, the question on how the mapping between Syntax and the Interface takes place for the assignment of focus is explored in section 5.1. Specifically, Miyagawa's (2010) analysis is presented and abandoned in 5.1.1. Slioussar's model for Russian is looked at in section 5.1.2. Her model—with some modifications - has a certain degree of explanatory power for Greek VOS. Some concluding remarks appear in section 6 . 


\section{Word Order Permutations in Greek}

Greek has overt morphological case, which results in a high level of flexibility in the possible word order options ${ }^{1}$ (i.e. SVO, VOS, VSO, OVS, SOV, and OSV). ${ }^{2}$ Consider, for instance, the following examples:

(1) o Tianis padrevete ti the-MDA-nom John-nom is-marrying-3sg the-FDA-acc Mary-acc

'John is marrying Mary'

(2) A: emaقes ta nea?

learnt-2sg the-NDA-acc news-acc?

'Did you hear the news?'

padrevete ti Maria o rianis

is-marrying-3sg the-FDA-acc Mary-acc the-MDA-nom John-nom

VOS

'John is marrying Mary'

(3) A: emaقes ta nea?

learnt-2sg the-NDA-acc news-acc?

'Did you hear the news?'

$\begin{array}{lllll}\text { padrevete } & \mathrm{o} & \text { Tianis } & \mathrm{ti} & \text { Maria }\end{array}$

is-marrying-3sg the-MDA-nom John-nom the-FDA-acc Mary-acc

'John is marrying Mary'

(4) TI MARIA (oxi tin Eleni) padrevete o $\quad$ Tianis the-FDA-acc Mary-acc (not Helen) is-marrying-3sg the-MDA-nom John-nom 'It is Mary that John is marrying'

(5) o Tianis TI MARIA (oxi tin Eleni) padrevete the-MDA-nom John-nom the-FDA-acc Mary-acc (not Helen) is-marrying-3sg

'It is Mary that John is marrying'

(6) A: ema $\theta$ a padrevete o Tianis

learnt-3sg is-marrying-3sg the-MDA-nom John-nom

'I've heard that John is getting married'

pia perni? tin Eleni?

who-acc-fem is-taking-3sg? the-FDA-acc Helen-acc?

'Who to? Helen?'

1) The word orders in (1)-(6) are also attested with the presence of an object clitic. The object clitic, however, alters the information structure of the sentence. This work will not deal with these possible and widely attested instantiations (for a discussion of these cf. Kechagias 2010).

2) If we were to support a cartographic approach, the alternative is to assume that it is not morphological case that triggers different word orders, but the availability of distinct information structure-related projections. 


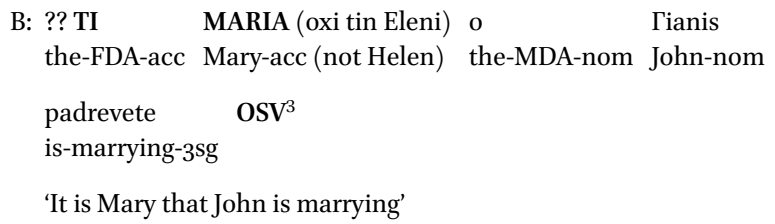

The OVS, SOV, and OSV word order options seem to be acceptable only when the object is contrastively focused and receives the main stress of the clause as indicated by the bold capitals (for a different view see Gryllia 2008). As a matter of fact, (4), (5), and (6) could come as an answer to Speaker A's question in (6). The preference for one word order over another in Greek is not purely a matter of grammaticality—unlike in English—but is heavily dependent on information structure, encoded by the different order of the arguments (cf. Georgiafentis 2001; 2003, Philippaki-Warburton 2001, Alexiadou 1999, and Kechagias 2010 for an alternative view).

NSLs like Greek have the option of allowing null subjects, as in (7):

(7) ayorase aftokinito

bought-3sg car-acc

'He/She bought a car'

Moreover, NSLs display at least one type of subject-inverted order-VOS and VSO in Greek - as we have seen in (2) and (3), respectively. Verb-initial orders are available in other NSLs like Spanish and Italian with various restrictions (cf. Zubizarreta 1998 and Belletti 2001, 2004). ${ }^{4}$ Several studies have looked into subject-inverted orders in Greek. Most of the literature has focused on VSO (cf. Alexiadou 1999; 2000, Philippaki-Warburton 2001, Roussou and Tsimpli 2006, etc) whereas others have also looked at VOS (Sifaki 2003, Georgiafentis 2001; 2003, Kotzoglou 2006, Haidou 2004, Gryllia 2008, and Kechagias 2010, inter alia).

The literature almost exclusively discusses VOS in main clauses. Before we examine data from embedded VOS, in the next section we will investigate the information structure properties of main VOS.

\subsection{Focusing Patterns in Main VOS}

The term focus has come to be associated with new and contrastive information as well as with the primary stress of the sentence. On the other hand, the

\footnotetext{
3) One of the reviewers points out that B's response in (6) in which an element intervenes between a preverbal focus and a verb sounds less acceptable. Yet, it is not ungrammatical.

4) Not all NSLs exhibit both verb-initial orders. Italian, for instance, does not permit VSO.
} 
term topic signals given or old information. I will not deal here in any detail with topics except in the broadest sense; that is, whatever is not a focus is a topic (see Hinterhölzl 2000; 2009 and Gryllia 2008 for a finer distinction of topics).

Before we discuss in some detail the narrow focusing patterns available in VOS, it is important to mention that, as in (2), VOS can come as all new information (wide focus) or as a vivid description in a narrative. In this case no particular constituent is marked as focused, given that the whole sentence is new to the hearer:

(8a) A: yia lege.

so say-2sg

'So, go on'

B: aniyi tin porta i Maria ke ti na di? ${ }^{5}$

opens-3sg the-FDA-acc door-acc the-FDA-nom Mary-nom and what to see-3sg

'Mary opens the door and what do you think she gets to see?'

(8b) A: ðiavases efimeriða?

read-3sg newspaper-acc?

'Did you read the paper?'

aniyi tis portes tis yia Elines metanastes

is-opening-3sg the-FDA-acc doors-acc of-her-acc for Greek immigrants

i Afstralia.

the-FDA-nom Australia-nom

'Australia is opening its doors to Greek immigrants'

(8a) is part of a narrative in which the speaker is telling a story about Maria and (8b) functions as introducing a new topic of conversation. This wide focus interpretation is available in both VOS and VSO orders. The current work will not deal with wide focus (sentence-focus in Lambrecht's 1994 terms) VOS interpretations, but only with narrow focus ones (i.e. when new information marks a specific constituent). ${ }^{6}$

\footnotetext{
5) Ordoñez (1998) shows that VOS in Spanish is tolerated only in embedded and interrogative environments.

6) One of the reviewers raises an interesting question at this point, that is how the wide focus interpretation structures in (8) fit with the analysis proposed for narrow focus VOS. Syntactically, I assume that narrow and wide focus VOS do not differ in the way they are derived. In terms of their information structure, however, the examples in (8) seem to render Slioussar's (2007) accessibility criterion inert. Intuitively, the examples in (8) are similar to the VSO examples that Philippaki-Warburton (2001) labels as 'unmarked', unmarked because they lack a specific focus
} 
In (9), (10), and (11) focus may mark the subject (contrastively), the verb and the object, respectively. The examples in (a) exhibit definite (specific) objects, whereas the examples in (b) involve indefinite (non-specific) objects:

(9a) A: telika, ti ekanan ta peðia su metis exetasis? finally what did-3pl the children of-yours with their exams

'In the end, what did your children do with their exams?' $\begin{array}{llllll}\text { B: perase } & \text { tis } & \text { exetasis } & \text { I } & \text { MARIA } & \text { (oxi o } \text { Tianis) }^{7} \\ \text { passed-3sg } & \text { the-FDA-acc } & \text { exams-acc } & \text { the-FDA-nom } & \text { Mary-nom } & \text { (not John) }\end{array}$

'Mary passed the exams'

(9b) A: kanena neo apo to metopo eryasias?

any news from the-NDA-acc frontier-acc employment-gen

'Any news on the employment frontier?'

B: vrike đulia I MARIA (oxi o Гianis)

found-3sg job the-FDA-nom Mary-nom (not John)

'Mary found a job'

interpretation. Moreover, Roussou and Tsimpli (2006), comment that these VSO cases have led researchers to characterize such structures as representing the basic word order in Greek. Surprisingly, the literature (i.e. Georgiafentis 2001; 2003, Sifaki 2003, inter alia) has largely overlooked wide focus VOS and their derivation. By lacking a specific focus interpretation, wide focus VOS renders the cartographic approaches and the generation of specific focus projections even more uneconomical. I have no further insight to offer here, but wide focus VOS is certainly worthy of future attention (see also footnote 8).

7) In order to test how felicitous VOS structures with narrow or contrastive focus are, it is necessary that we embed these in a context. For instance, contrastive focus is not tolerated in an existential structure like (a):

(a) eyine samatas

was-3sg argument

'There was an argument'

Narrow focus too would be hard to argue in (a). Similar problems arise with event structures. Based on Lambrecht (1994: 223), an eventive interpretation only occurs when the proposition contains no presupposition, as in (b):

(b) John was arrested for theft.

This is an event structure only if it came as an answer to the question 'What happened', but not if it came as an answer to 'What happened to John' (cf. Kuroda (1972), Lambrecht (1994) and Kechagias (2010) on thetic and categorical judgments). A separate study is required to show which environments tolerate contrastive focus and which don't. For the purposes of this work, however, such limitations on the naturalness of VOS with narrow (or contrastive) focus can be obviated with the use of an appropriate context. Thanks to the reviewer for bringing this to my attention. 
(10a) A: ti ekane i Maria me tis exetasis? what did-3sg the-FDA-nom Mary-nom with the-acc exams-acc

'What did Mary do with her exams?'

B: *(telika), PERASE, tis exetasis i Maria ke (finally) passed-3sg the-FDA-acc exams-acc the-FDA-nom Mary-nom and efiye yia Ameriki ${ }^{8}$ left-3sg for States '(In the end) Mary did pass the exams and went to the States'

(10b) A: tipote neotero me ti Maria? nothing new with the-FDA-acc Mary-acc

'Anything new with Mary?'

B: *(telika), VRIKE ðulia i Maria ke efiye yia Ameriki ${ }^{9}$ (finally) found-3sg job the-FDA-nom Mary-nom and left-3sg for States

'(In the end) Mary did find a job and went to the States'

8) Anna Roussou (p.c) observes that in VOS, focus/stress cannot mark only the verb as below:
(a) (*ta)
EPLINE ta
piata
Maria
the-NDA-acc washed-3sg the-NDA-acc dishes-acc the-FDA-nom Mary-nom

'Mary washed the dishes'

(a) is ungrammatical without the presence of an object clitic before the verb. The only way for (a) to be accepted without an object clitic would be to function as an echo sentence, for example as an answer to the question epline ta piata $i$ Maria? where the answer echoes the word order of the question. However, I do believe that focus may mark the verb provided this is preceded by an XP as in (10a). I remain agnostic as to why an XP adverb like telika needs to appear clause-initially (cf. Pinto (1997), Zubizaretta (1998), Holmberg and Nikanne (2002) and section 4.1). I guess, and I agree with the reviewer on this point, that perhaps the adverb telika may simply be there to mark more clearly the interpretation of a verb-initial order in Greek. Similar type of XPs (primarily adverbs) are also discussed in Holmberg and Nikanne (2002: 81) who argue that the EPP can be satisfied by categories that are referential in a broader sense (i.e. locative and temporal adverbials, but not manner ones). Surely, I cannot think of a manner adverb performing a similar function here.

9) One of the reviewers argues that in order for stress to fall on the verb in cases in which the object is specific, an object clitic needs to precede the verb:

(a) tis PERASE tis exetasis i Maria

the same need for a clitic is not observed in cases in which the object is non-specific:

(b) (* ti) VRIKE ðulia i Maria

I do agree with the reviewer that the object clitic rectifies the ungrammaticality of (a), but is not needed in (b). However, I still believe that (a) may be rescued with an XP clause-initially and an XP is also (possibly less so) required for (b). Neither the clitic nor the XP are candidates for focus/stress. 
(11a) A: sta ipa ta nea?

you-gen.them-acc told-1sg the-acc news-acc

'Did I tell you the news?'

B: perase TIS EXETASIS i Maria ke efije yia

passed-3sg the-FDA-acc exams-acc the-FDA-nom Mary-nom and left-3sg for

Ameriki

States

'It was the exams that Mary passed and went to the States'

(11b) A: sta ipa ta nea yia ti Maria?

you-gen.them-acc told-1sg the-acc news-acc for the-FDA-acc Mary-acc

'Did I tell you the news about Mary?'

B: vrike ĐULIA i Maria ke efiye yia Ameriki

found-3sg job the-FDA-nom Mary-nom and left-3sg for States

'It was a job that Mary found and went to the States'

With an appropriate context other than the one provided, ${ }^{10}$ the focused constituents in (10) and (11) may also receive contrastive focus. The use of a specific or a non-specific object does not affect the focusing patterns of these structures, but it can affect the acceptability of (10). When the object is specific as in (10a), either we have to insert clause-initially an XP adverbial like telika, or a preverbal object clitic. The clitic is not necessary in (1ob), but I still believe that the XP adverb is. ${ }^{11}$ Whatever element is located clause-initially, the main point is that VOS cannot survive as Vl. The presence of a clitic should not have an impact on the analysis proposed in section 5.1.2. After all, monosyllabic and weak pronoun elements are not eligible candidates for focus or stress. A discussion on Clitic VOS falls outside the scope of this work (see Kechagias 2010).

Alexiadou (1999) and Georgiafentis (2001) realise that (11) can occur with comma intonation before the subject:

(11c) perase TIS EXETASIS, i Maria

passed-3sg the-FDA-acc exams-acc the-FDA-nom Mary-nom

'It was the exams that Mary passed'

10) (11b) would assign contrastive focus to the object if it appeared as an answer to (a) below:
(a) A: perni epiðoma aneryias i Maria?
receives-3sg benefit unemployment-gen the-FDA-nom Mary-nom
'Is Mary on unemployment benefit?'
11) (1ob) may sound marginally better than (10a) even without the use of an adverb. 
The subject in (11c) constitutes old information and the analysis they both advocate is subject right dislocation, for those, of course, who find right adjunction a legitimate derivational operation (cf. Kayne 1994 against rightward adjunction). If an element does not constitute new information, then it will necessarily be realised as background/old information. As a result, in a structure like (11c) either the verb or the object will be focused.

In (gb) the subject bears the focus/stress of the sentence. In Zubizarreta's (1998) terms, the subject $i$ Maria is assigned contrastive focus, that is $i$ Maria is contrasted with some other individual, i.e. Fianis. Contrastive focus may also have a metagrammatical function indicating correction of a proposition that the hearer assumes. ${ }^{12}$ The speaker seems to make it clear that it was Maria who passed the exams and not Fianis. Kiss (1998) argues that there are two types of foci; new information/presentational focus and contrastive focus. With evidence from Hungarian, she tries to show that postverbal elements receive presentational focus and preverbal ones receive contrastive focus.

Even though the subject in VOS may receive only contrastive focus, the object may be marked with either new information or contrastive focus. Gryllia (2008), contra Roussou and Tsimpli (2006) and Kiss (1998), convincingly demonstrates that in Greek postverbal objects do not always encode new information/presentational focus and that preverbal focus is not always contrastive. On the basis of experimental tests, Gryllia argues that preverbal objects are not always either exhaustive or contrastive. VO and $\mathrm{OV}$ with object foci may be interpreted as new information, or as contrastive, as in (12) and (13), respectively:

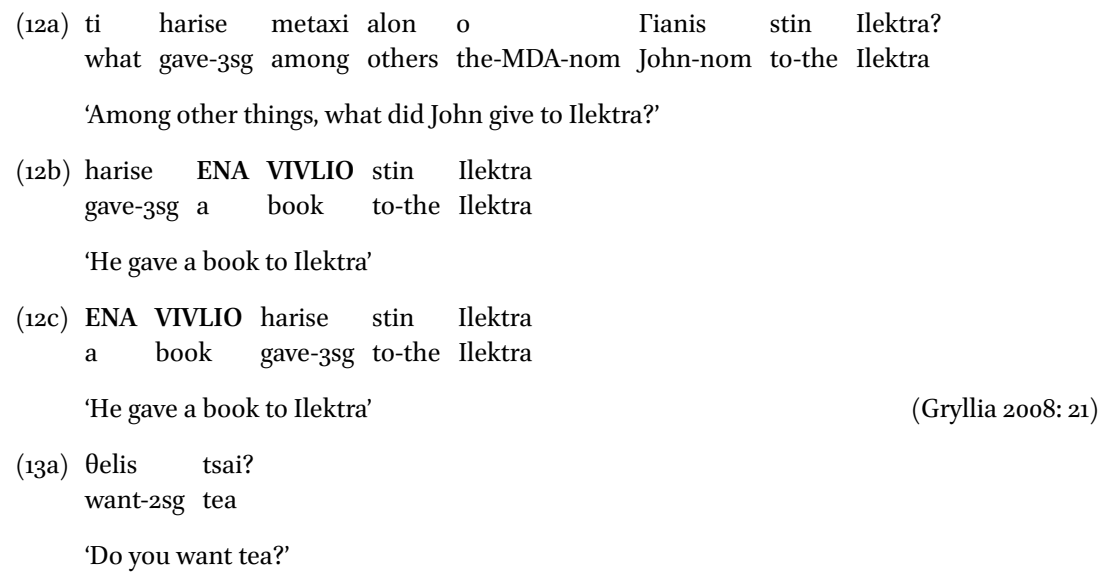

12) Throughout this paper I will be using 'contrastive' focus to refer to both contrastive and corrective focus. 
(13b) oxi, Өelo KAFE

no, want-1sg coffee

'No, it's coffee I want'

(13c) oxi, KAFE Өelo

no, coffee want-1sg

'No, it's coffee I want'

(Gryllia 2008: 54)

Based on Gryllia's evidence that postverbal objects do not always constitute new information I will assume the following: (a) contrastive focus, in principle, could occur anywhere in the sentence, and (b) on the basis of assumption (a) the two types of foci (new and contrastive) cannot have distinctly designated syntactic positions (i.e. FocC(ontrastive) and FocI(nformation) in the clausal architecture à la Rizzi (1997).

\subsection{Adverbs in VOS}

It is interesting to see that in the presence of a manner adverb in VOS two patterns emerge: (a) the adverb necessarily follows the verb, and (b) the adverb may carry the focus of the sentence:
(14a) ayapai PARAFORA to
Гioryo i Maria
VAdvOS $^{13}$
loves-3sg besottedly the-MDA-acc George-acc the-FDA-nom Mary-nom
'Mary loves George besottedly'
13) On a par with (10a), (14a) could also appear with an object clitic. On the other hand, the use of a non-specific object as in (a)-(d) suggests that specificity (or lack of) does not affect the focusing patterns of VAdvOS:
(a) vrike AMESOS ðulia i Maria/*vrike ðulia amesos i Maria/*vrike ðulia i Maria amesos found-3sg immediately job the-FDA-nom Mary-nom
'Mary found a job immediately'
(b) *VRIKE amesos đulia i Maria found-3sg immediately job the-FDA-nom Mary-nom
'Mary did find a job immediately'
(c) *vrike amesos ĐULIA i Maria
found-3sg-past immediately job the-FDA-nom Mary-nom
'Mary found a job immediately'
(d) * vrike amesos ðulia I MARIA found-3sg immediately job the-FDA-nom Mary-nom 'It was Mary who found a job immediately'



(14b) *ayapai to Tioryo parafora i *VAdvS loves-3sg the-MDA-acc George-acc besottedly the-FDA-nom Mary-nom 'Mary loves George besottedly'
(14c) *ayapai to Tioryo i Maria parafora *VOSAdv 'Mary loves George besottedly'14

As a matter of fact, if focus falls on any other constituent than the manner adverb, then this will be contrastive and it will have to fall on the object:
(15a) A: fos fanari oti ine erotevmeni i Maria, obvious that is-3sg in-love-fem the-FDA-nom Mary-nom
'It is obvious that Mary is in love.'
les na yirise ston proin tis?
say-2sg that have-returned-3sg to-the-MDA-acc ex-acc of-her-gen
'Do you think she went back with her ex?'

14) For a different viewpoint on where a manner adverb can surface in a VOS order see Alexiadou (1999) and Kechagias (2010). Kechagias (2010) argues that the manner adverb in these cases can appear only between the object and the subject as illustrated in (a):

(a) eno ola itan irema, xafnika, klotsai mia bala ðinata ena peði while all was quiet suddenly kicks a ball hard a child

'while it was all quiet, all of a sudden, a kid kicks the ball hard'

(Kechagias 2010: 63)

On the basis of his acceptability pattern, Kechagias (a) refutes right adjunction analyses of the subject and (b) shows that $\mathrm{V}+\mathrm{O}$ move to the specifier of TP (with a few variations). Unlike Kechagias, the acceptability pattern $\mathrm{I}$ am advocating here shows rather the opposite, namely that $\mathrm{V}+\mathrm{O}$ cannot move together if their sequence is interrupted by a manner adverb. He also finds the same acceptability pattern for embedded VOS:

(b) $\theta$ a ekplayo mono an lisi tin askisi yriyora $\quad$ Aris will surprise only if solves the problem quickly the-MDA-nom Aris-nom

'I will be surprised if Aris solves the problem quickly'

Alexiadou (1999) also rejects the VadvOS order, but on the basis that the adverb and the object compete for the same position in the syntactic tree and as a result the adverb cannot surface immediately after the verb. I do not share the same judgment, and I still find (c) ungrammatical:
(c) * Maria apokalipse oti ayapai to Гioryo the-FDA Mary-nom revealed-3sg that loves-3sg the-MDA-acc George-acc
parafora i Eleni
besottedly the-FDA-nom Helen-nom
'Mary revealed that Helen loves George besottedly'

I do expect variation among speakers on the acceptability of the examples above and I am also aware that speakers may find both VadvOS and VOadvS marked. 
B: aðinaton! ayapai parafora TO TIANI (oxi to Niko) i

impossible! loves-3sg besottedly the-MDA-acc John-acc (not Nick) the-FDA-nom

Maria.

Mary-nom

'Impossible! It is John that Mary loves besottedly'

(15b) B: aðinaton! *ayapai parafora to Tiani I MARIA impossible! loves-3sg besottedly the-MDA-acc John-acc the-FDA-nom Mary-nom 'Impossible! Mary loves John besottedly'

$(15 \mathrm{~b})$ is ungrammatical whether the subject receives new information or contrastive focus.

Following Cinque (1999), adverbs generate their own functional projections in the syntactic architecture and do not constitute adjuncts (cf. section 5$) \cdot{ }^{15}$ If the adverb occupies a separate projection, then an analysis of Greek VOS in which there is VP movement (i.e. $\mathrm{V}+\mathrm{O}$ ) cannot be postulated (cf. section $5)$.

\subsection{Embedded VOS}

VOS accounts have looked primarily into data from Greek matrix clauses. However, the literature has largely overlooked whether the focusing possibilities that hold in main clauses are also borne out in embedded VOS. Judgments between speakers may vary regarding the sentences below. (16) features embedded clauses introduced with the connector otan. (16a) reveals that focus may fall on the verb. ${ }^{16}$ However, (16b) and (16c) are marginal if new information focus falls on the object or on the subject. These sentences would be acceptable only if contrastive focus fell on the object ( $16 \mathrm{~b})$ and the subject (16c), respectively. Again, the sentences in $\left(16 a^{\prime}\right),\left(16 b^{\prime}\right)$ and $\left(16 c^{\prime}\right)$ have a non-specific object. As with main VOS, object specificity does not play a role on the focusing patterns we observe in embedded clauses.

\footnotetext{
15) Cinque (1999) does claim that if the adverb is to be focused it will be located after the subject (at the end) and not outside the VP-domain. His evidence comes mainly from Italian.

16) One of the reviewers justifiably asks whether verbal focus is the same in main and subordinate clauses. Ideally, I would like to say that it is. However, the pattern is such that in order for the verb to receive focus in main and subordinate clauses different elements have to precede it (i.e. XP/object clitics vs. connectors/complementizers). The issue deserves lengthier, preferably corpus-based empirical observations, and without these, I will have to refrain from commenting any further.
} 
(16a) otan TELIOSE to sxolio i Maria, o when finished-3sg the-NDA-acc school-acc the-FDA-nom Mary-nom the-MDA-nom rianis itan iði ðiðaktorikos fititis

John-nom was-3sg already PhD student

'When Mary did finish school, John was already a PhD student'

$\left(16 a^{\prime}\right)$ otan PIRE ptixio i Maria, o rianis when got-3sg degree-acc the-FDA-nom Mary-nom the-MDA-nom John-nom itan iði ðiðaktorikos fititis was-3sg already PhD student 'When Mary did get her degree, John was already a PhD student'

(16b) ??otan teliose TO SXOLIO i Maria, o when finished-3sg the-NDA-acc school-acc the-FDA-nom Mary-nom the-MDA-nom

Tianis itan iði ðiðaktorikos fititis John-nom was-3sg already PhD student

'When Mary finished school, John was already a PhD student'

$\left(16 b^{\prime}\right)$ ??otan pire PTIXIO i Maria, o when got-3sg degree-acc the-FDA-nom Mary-nom the-MDA-nom John-nom itan iði ðiðaktorikos fititis was-3sg already PhD student

'When Mary got her degree, John was already a PhD student'

(16c) ??otan teliose to sxolio I MARIA, when finished-3sg the-NDA-acc school-acc the-FDA-nom Mary-nom

o $\quad$ Tianis itan iði Ameriki the-MDA-nom John-nom was-3sg already America 'When Mary finished school, John was already in the States'

$\left(16 c^{\prime}\right)$ ??otan pire ptixio I MARIA, o when got-3sg degree-acc the-FDA-nom Mary-nom the-MDA-nom John-nom itan iði ðiðaktorikos fititis was-3sg already PhD student

'When Mary got her degree, John was already a PhD student'

In the case of another connector, afou, (17) shows that the status of afou-clauses is even more degraded than that of otan clauses when information focus marks the subject, the object, or the verb. The acceptability of the examples in (17) would be considerably improved, if contrastive focus fell on the focused constituents in bold. ${ }^{17}$

17) Again, a non-specific object does not alter the pattern we find in (17): 
(17a) ???afou ayapai ti Maria 0 ГIANIS,

since loves-3sg the-FDA-acc Mary-acc the-MDA-nom John-nom

ðen katalaveno yiati ðen ipoxori o lefteris

not understand-1sg why not steps-back-3sg the-MDA-nom Lefteris-nom

'Since John loves Mary, I don't understand why Lefteris does not back off'

(17b) ?afou ayapai TI MARIA o

since loves-3sg the-FDA-acc Mary-acc the-MDA-nom John-nom

ðen katalaveno yiati flertari me tin Ariaðni

not understand-1sg why flirts-3sg with the-FDA-acc Ariadne-acc

'Since John loves Mary, I don't understand why he flirts with Ariadne'

(17c) ??afou AГAPAI ti Maria o

since loves-3sg the-FDA-acc Mary-acc the-MDA-nom John-nom

ðen katalaveno yiatiflertari me tin Ariaðni ${ }^{18}$

not understand-1sg why flirts-3sg with the-FDA-acc Ariadne-acc

'Since John does love Mary, I don't understand why he flirts with Ariadne'

The an-clauses in (18) pattern similarly to the afou-clauses. Information focus on the subject is not tolerated. Whereas afou-clauses seem to prefer information focus on the object, an-clauses seem to prefer focus on the verb, as shown in (18b). Again, constrastive focus may mark any constituent.

(18a) A: ti se rotusan ap tin trapeza?

what you-acc were-asking-3pl from the-FDA-acc bank-acc

'What were they asking you from the bank?'

B: ???rotusan an pire tin apozimiosi/apozimiosi I

were-asking-3pl if got-3sg the-FDA compensation-acc the-FDA-nom Mary-nom

'They were asking whether Mary got the/ø compensation'

(a) ???Afou vrike ðulia I MARIA, ðen katalaveno yiati ðen ayorazi spiti

(b) ?Afou vrike ĐULIA i Maria, ðen katalaveno yiati ðen ayorazi spiti

(c) ?Afou VRIKE đulia i Maria, ðen katalaveno yiati ðen ayorazi spiti

I have tested all examples in this paper with a specific and a non-specific object. Due to space limitations, I do not always choose to mention the non-specific object constructions, especially when there are no significant acceptability differences from their specific object counterparts.

18) As with previous examples, $(17 \mathrm{c})$ would be less marginal if an object clitic preceded the verb.

19) One of the reviewers finds all sentences in (18) grammatical, but I still cannot see how these cases can receive new information focus. The only focus readings I seem to get are those in which the focused elements indicate contrast. 
(18b) B: ?rotusan an PIRE tin apozimiosi/apozimiosi i were-asking-3pl if got-3sg the-FDA-acc compensation-acc the-FDA-nom

Maria

Mary-nom

'They were asking whether Mary did get the/ø compensation'

(18c) B: ??rotusan an pire tin APOZIMIOSI/APOZIMIOSI i

were-asking-3pl if got-3sg the-FDA-acc compensation the-FDA-nom

Maria

Mary-nom

'They were asking whether Mary got the/ø compensation'

The na-clauses in (19) seem to allow the verb or the object to be marked with information focus, but the subject cannot be marked with information focus, only with contrastive:

(19a) o Tianis ipe na PARI tin apozimiosi/apozimiosi the-MDA-nom John-nom said-3sg that get-3sg the-FDA-acc compensation-acc

i Maria ke meta pane ðiakopes the-FDA-nom Mary-nom and then go-3pl holidays

'John said that Mary should get the/ø compensation and then they will go on holidays'

(19b) o Tianis ipe na pari TIN APOZIMIOSI/APOZIMIOSI the-MDA-nom John-nom said-3sg that get-3sg the-FDA-acc compensation-acc

i Maria ke meta pane ðiakopes the-FDA-nom Mary-nom and then go-3pl holidays

'John said that Mary should get the $\varnothing \varnothing$ compensation and then they will go on holidays'

(19c) ??o $\quad$ Tianis ipe na pari tin apozimiosi/apozimiosi

the-MDA-nom John-nom said-3sg that get-3sg the-FDA-acc compensation-acc

I MARIA ke meta pane ðiakopes ${ }^{20}$

the-FDA-nom Mary-nom and then go-3pl holidays

'John said that Mary should get the $/ \varnothing$ compensation and then they will go on holidays'

Let us now consider oti complement clauses. On a par with na-clauses, oticlauses permit the verb and the object to receive information focus, but the subject can only be assigned contrastive focus.

20) Stress on the subject here could be either contrastive or default. 


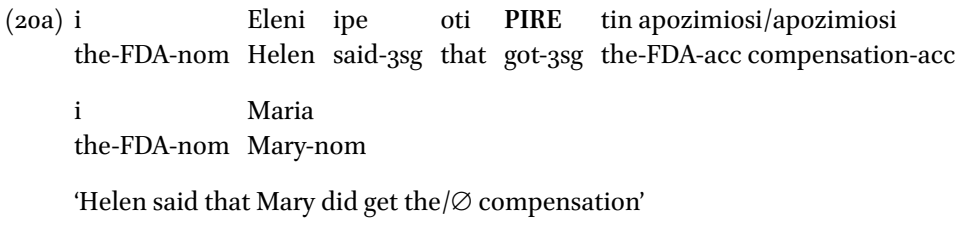

In conclusion, otan, afou and an- clauses seem to have limited focusing possibilities. In these clauses when an element receives focus, then the focus interpretation is most likely to be contrastive. On the other hand, $n a$ and oti-clauses in terms of their focusing possibilities resemble main VOS clauses. In addition, whether the object is a specific or a non-specific DP, the focusing patterns are not affected. Table 1 below summarises the focusing patterns exhibited in otan, afou, an, na, and oti clauses:

Table 1.

\begin{tabular}{ll}
\hline Embedded + VOS & New Information Focus \\
\hline Otan + & VOS \\
Afou + & ? VOS \\
$\mathrm{An}+$ & ? VOS \\
$\mathrm{Na}+$ & VOS or VOS \\
$\mathrm{Oti}+$ & VOS or VOS \\
\hline
\end{tabular}

The question that emerges here is why the embedded domain does not permit the same focusing possibilities as the main one does and how we can explain the asymmetry between na/oti on the one hand and the rest of the connectors (see Rizzi 1997).

The subject in otan, afou and an clauses seems to constitute background information or else what the topic of discourse is about. It is not surprising that the subject in these cases cannot receive new information focus. However, the same observation holds true for $n a$ and oti clauses, even though these 
seem to behave more like main VOS. Palmer (2009) makes some interesting points regarding the information structure in main and subordinate clauses in Cheke Holo. He comes to the conclusion that subordinate clauses tend to further elaborate upon material that has already been introduced in the discourse which is why they differ in their focusing possibilities from the main clauses.

Given how much the focusing possibilities of embedded VOS differ from those of main VOS, the data from otan, an and afou subordinate clauses do not support the presence of a fixed Focus Projection in the clausal architecture. ${ }^{21}$

\section{Previous Accounts on Greek VOS}

Distinct theories are trying to account for focus assignment in VOS either through prosodic movement or through fixed syntactic focus positions in the clausal architecture (as in Belletti 2001; 2004 based on Rizzi 1982). The information-structure properties of verb initial orders in Greek have motivated a number of analyses (cf. Philippaki- Warburton 2001, Georgiafentis 2001; 2003, Alexiadou 1999; 2000; 2006, inter alia) that view the derivation of VOS and VSO as prosodically-driven movement (in the spirit of Zubizarreta 1998). ${ }^{22}$ Roughly speaking, according to Cinque (1993) the $\mathrm{N}$ (uclear)S(tress) $\mathrm{R}$ (ule) regulates that stress should fall on the most deeply embedded constituent in the clausal structure, whereas the $\mathrm{F}$ (ocus) $\mathrm{P}$ (rominence) $\mathrm{R}$ (ule) assigns focus to the most prominent element. ${ }^{23}$

Under Zubizarreta's reasoning, a constituent which is not supposed to receive the main prominence, but for syntactic reasons is in the lowest node in the c-command ordering (where the NSR assigns main prominence) has to be displaced to a higher position. In this way, it allows another constituent (i.e. the focused one) to end up in the lowest position in the c-command ordering, and thus receive the main stress via the NSR. This prosodically driven movement takes place in the syntax, and is there to resolve a prosodically

21) Another tacit pattern derived from paradigms (16)-(20) indicates that contrastive focus is the default focus pattern in embedded VOS should information focus on a lexical element fails to be assigned. A detailed discussion on contrastive and information focus falls outside the remit of this paper, but is an observation worth exploring in the future.

22) Zubizarreta (1998) does not necessarily postulate Focus and Topic projections. With respect to Spanish she argues that topic and focus are borne as features by T.

23) Focus Prominence Rule:

Given two sister categories $\mathrm{Ci}($ marked $[+\mathrm{F}]$ ) and $\mathrm{Cj}$ (marked $[-\mathrm{F}]), \mathrm{Ci}$ is more prominent than $\mathrm{Cj}$.

(Zubizarreta 1998: 21) 
contradictory situation. Consequently, prosodically driven movement is not driven by feature-checking considerations. Regarding its type, Zubizarreta shows that it is an A-bar movement since it does not affect any binding relations.

Alexiadou (2000) argues that in VOS order we encounter only one prosodic pattern, that is where the subject is stressed. ${ }^{24}$ The syntactic derivation in her account proceeds as below, VOS being analysed as object shift:

$(21)$

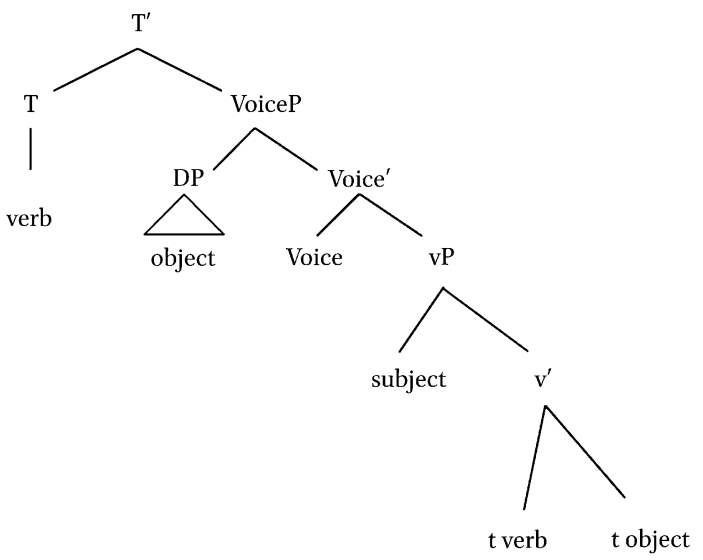

The verb moves to $\mathrm{T}$ for checking reasons, and the usual VSO order is generated. SpecTP is absent in her system since Greek patterns like a VSO language, in which SpecTP is not licensed due to its weak N-features. Proceeding in the derivation, the object moves to SpecVoiceP, an A-position (similar to scrambling) ${ }^{25}$ The reasoning behind the postulation of a VoiceP, is that

24) In Alexiadou (1999), it is mentioned that VOS with focus on the subject is more acceptable in the presence of a clitic.

25) Alexiadou (1999) argues that binding evidence from Greek is not conclusive on what type of movement is instantiated with VOS (A-object scrambling or A-bar). Kechagias (2010) presents the following data:

(a) tromokratise ton eafto tis i Maria

scared the self-of-her the-FDA Mary

'Mary scared herself'

(b) de sevastike [ton eafto tou $]_{\mathrm{i}}$ o Aris $_{\mathrm{i}}$

not respected him self of-his the-MDA-nom Aris-nom

'Aris did not respect himself'

(Kechagias 2010: 69-70)

Principle $\mathrm{C}$ is not violated here because there is no c-command. However, given that the above also abide by Principle A (or at least do not violate principle A) it must mean that there is some reconstruction (evidence towards A-bar movement) taking place. Yet again, as Kechagias correctly 
scrambled objects and manner adverbs seem to compete for the same position in Greek. Since the position to which manner adverbs move in Greek according to Alexiadou has been identified with VoiceP, scrambled objects have to move there as well. ${ }^{26}$ Thus, VOS is generated in which the DP-subject ends up in a position where it can receive the main accent via the NSR (i.e. the lowest c-commanding position). She maintains that the object movement to VoiceP is similar to the prosodically-driven movement proposed by Zubizarreta (1998) for Spanish. ${ }^{27}$

Georgiafentis (2001; 2003), based on Philippaki-Warburton (2001), puts forward three distinct derivational accounts to accommodate the three intonational patterns he identifies in VOS. VOS with focus on the object and where the subject is separated by a comma is illustrated below:
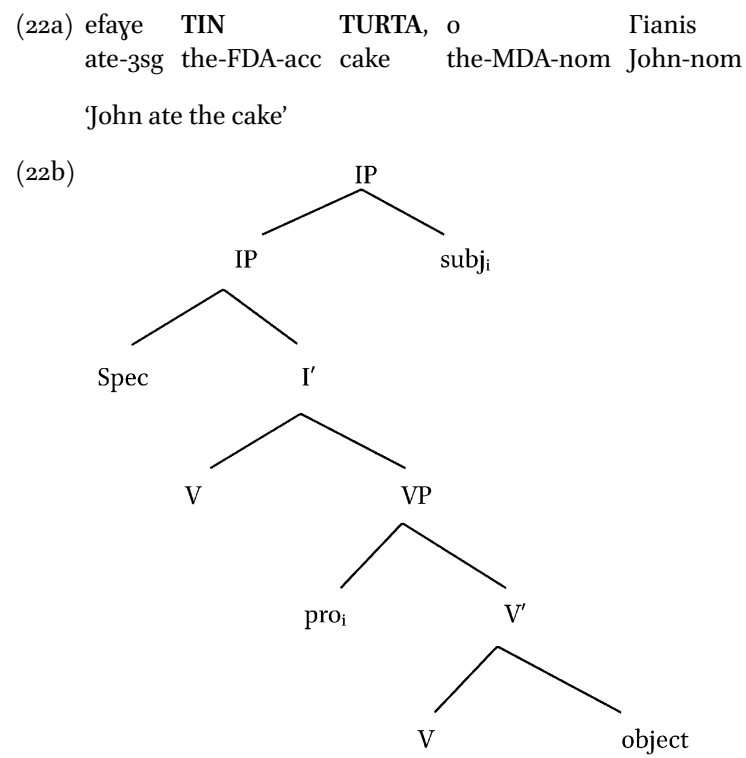

observes on the basis of legitimate sentences like (c) it looks like c-command even for anaphor binding may not be a reliable diagnostic (Alexiadou 1999 and Kechagias 2010:69):

(c) Himself $f_{\mathrm{i}}$, John likes most

(Kechagias 2010: 69, ft. 15).

The assumption entertained here is that movement of the object for EF satisfaction most likely instantiates A-bar movement (cf. footnote 41).

26) It is conceptually odd that objects and manner adverbs compete for the same position.

27) Alexiadou (2006) seems to have replaced VoiceP with FP. She also mentions that movement in VOS could be either prosodically driven movement (in the sense of Zubizaretta 1998) or just syntactic movement in the absence of conclusive evidence from binding. 
The subject in this case is right-IP adjoined and coindexed with a pro.

In the case in which the object receives the focus, but is not separated from the subject by comma, there is V-I movement and the subject is right adjoined to the vP, as below:

(23a) efaye TIN TURTA o Гianis

$(23 b)$

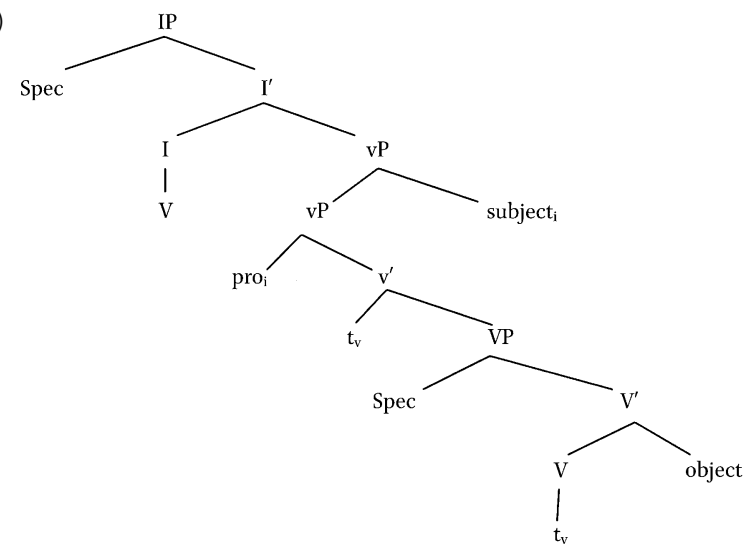

Lastly, when the subject receives the focus, there is V-I movement and then movement of the whole VP to the specifier of TopP:

(24a) efaye tin turta O ГIANIS

(24b)

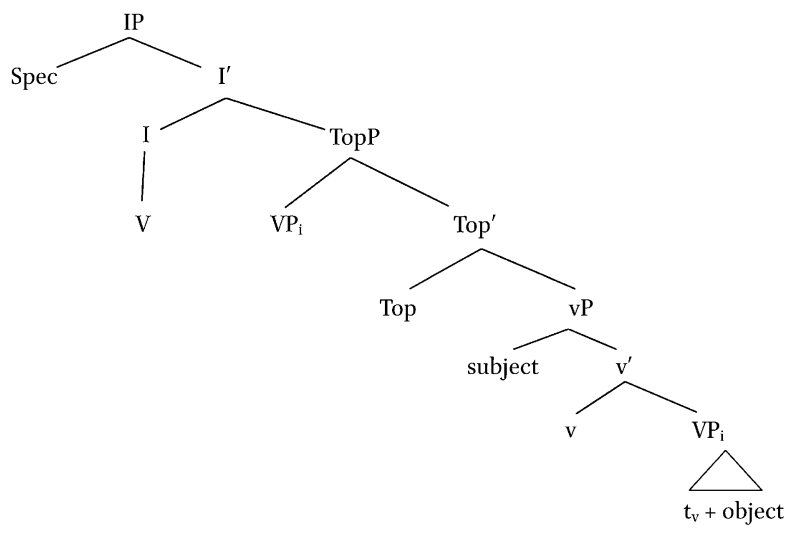

Relying on assumptions from Legate (2003) and her work on movement in and out of phases, Georgiafentis (2003) extends his account in the following manner. He assumes that whatever is handled in syntax is then assigned stress in the $\mathrm{P}$ (honetic) $\mathrm{C}$ (omponent). Yet, as the derivation above indicates, Georgiafentis (2003) still postulates movement of the VP to SpecTopP even if the interpretation of focus is assigned post-syntactically. As Georgiafentis (2003) himself 
acknowledges his account lacks any explanation of the trigger and the target of these movements.

I have further objections against Georgiafentis' three distinct derivations. In the third derivation, if a TopP exists, then the lexical elements must enter the derivation fully specified with a focus feature. This assumption cannot be true. Focus and Topic are not inherent properties of lexical elements, but are idiosyncratic (cf. Kechagias 2010). Lastly, in the presence of a lexical subject, the simultaneous presence of a pro seems to be redundant. In traditional terms, pro is only available when the subject is absent (for a different view see Spyropoulos and Philippaki-Warburton 2001).

The above accounts seem to rely on prosodically driven movement as well as on aspects of the cartographic analyses. The cartographic approaches assume that movement in Syntax takes place for the satisfaction of a focus feature, a feature that appears in a corresponding Focus Projection. The cartographic accounts advocate that lexical elements are assigned focus during the course of the syntactic derivation. Let us consider in some detail theoretical and empirical arguments against the generation of Focus Projections in the clausal architecture.

\subsection{Against Focus Projections}

In the cartographic approaches, the phenomenon of focusing is analysed as movement to the specifier position of the functional projection of a Focus head. The interpretation of the raised focus element is brought about by Spec-head agreement in Focus Phrase (cf. Puskas 1992, Tsimpli 1992, Brody 1990, Kiss 1998, etc). Some authors identified the FocP position in the left periphery typically situating this projection in a Comp-like position (i.e., between CP and IP), or even as a phenomenon that targets the low IP area (i.e., above vP, cf. Belletti 2001; 2004). Most notably, Belletti (2001; 2004) builds an account of a Split-CP system as originally advocated by Rizzi (1997). Based on her account, the left periphery has a fixed Topic/Foc Projection generated in specific places in the syntactic tree.

Kechagias (2010) convincingly presents some arguments against such a cartographic account. Firstly, he argues that lexical items leave the numeration carrying only their agreement features. Lexical elements do not enter the derivation fully specified for topic and/or focus features. Topic and focus are relational concepts, namely they affect lexical elements in relation to other lexical items. Hence, it is very hard to predetermine which syntactic elements will carry focus. As Kechagias points out, focus may also affect units smaller or larger than words, namely may affect morphemes or even a whole sentence (all new information cases). If topic and focus are just syntactic features like any other 
agreement features, then focus markers or all new information sentences cannot be accounted for by a focus feature in a fixed syntactic position (for more details see Kechagias 2010, ch. 5) ${ }^{28}$

Nevertheless, a number of accounts argue that discourse related properties are not assigned in syntax, but post-syntactically (cf. Haidou 2000; 2012, Sifaki 2003, Costa 2004, Costa and Kula 2008, and Kechagias 2010 with some variations). These accounts dispense with any focus related projections or focusdriven movement in syntax. On the basis of evidence from Romance and Bantu languages, Costa and Kula (2008) show that the former language group does not support a specific syntactic focus position, whereas the latter group shows that it is almost impossible to link one prosodic effect to one designated focus position. If the requirement that a subject occurs in a low syntactic position to receive focus were true, then we would expect the same to hold true in embedded environments. As Costa and Kula show, this is not true in Portuguese:

(25a) querem ler todos os alunos esse livro want-3pl read all the students that book

'All the students want to read that book'

(25b) *recusaram ler todos os alunos esse livro refused-3pl read all the students that book

'All the students refused to read that book'

(25c) TODOS OS ALUNOS recusaram ler esse livro all the students refused to read that book

'All the students refused to read that book'

28) One such cartographic account for Greek with focus on the left periphery rather than on word order alternation is put forward by Roussou (2000). Roussou's system relies on Rizzi's (1997) split CP hypothesis. Specifically, she proposes (p. 79) the following structure of the C domain in the Greek system:

$[C$ pu/oti [Topic/Focus $[C$ op oti/an/na/as[NEG den/mi(n) $[C m \theta \mathrm{a} /$ na/as/gerunds $[C l P]]]]]]$

Her account accommodates cases like (a), but does not discuss any post-verbal foci (or in-situ foci) like (b). I assume that to account for (b) another Focus feature needs to be present in the right periphery.
(a)I Maria ipe 0 TIANIS na min pai. the-FDA-nom Mary-nom said-3sg the-MDA-nom John-nom that not go-3sg 'Mary said that John shouldn't go'
(b)ayapise PARAFORA ti Maria o Tianis loved-3sg besottedly the-FDA-acc Mary-acc the-MDA-nom John-nom 'John loved Mary besottedly'


(25d) *negaram ler todos os alunos esse livro denied to read all the students that book

'All the students denied to read that book'

(25e) TODOS OS ALUNOS negaram ler esse livro

all the students denied to read that book

'All the students denied to read that book'

(Costa and Kula 2008:6)

Similar facts have been observed with embedded VOS clauses in Greek (as shown in section 2.3). Costa and Kula (2008) conclude that if focus was a syntactic primitive, then we would be unable to account for the data above.

Greek does not only permit subject-inverted orders like VOS and VSO, but it also exhibits the pro-drop parameter. These facts raise questions on the mode of EPP satisfaction in its original formulation, as the subject requirement on SpecTP. Therefore, the next section is dedicated to the status of the EPP in Greek.

\section{EPP on $\mathrm{T}$ as the Subject Requirement}

EPP has been standardly assumed to represent a D-feature, namely an uninterpretable feature of a referential nature which when present requires a matching interpretable $\mathrm{D}$-feature to be found in the derivation. The category that bears this interpretable D-feature will either Internally Merge (i.e., move) from some position in the syntactic tree to SpecTP, or externally merge to SpecTP (as in the case of expletives).

The standard analysis of NSLs (as in Rizzi 1982) in relation to EPP-satisfaction was to assume that there is a covert pronoun (pro) which takes the place of the subject in the specifier of the Inflectional projection and picks up its properties from the Infl by virtue of the phi-features of the verb. Alexiadou and Anagnostopoulou (1998), argue that the agreement properties of the verb can delete the requisite D-feature of the EPP on I through V-I raising. Nevertheless, their account runs into problems with verb initial impersonal constructions from Greek and other NSLs. As first noted by Spyropoulos and Philippaki-Warburton (2001), Greek existential and weather constructions that surface as verb-initial pose a problem to the satisfaction of the EPP in terms of V-I raising:

(26) ehi zesti

has-3sg heat

'It is hot'

(27) eyine samatas

was-3sg argument

'There was an argument' 
(28) epese hioni

fell-3sg snow

'It snowed'

(29) vrehi/hionizi

rains/snows-3sg

'It is raining/snowing'

Examples like (26), (27), (28), and (29) involve an impersonal verb which displays default 3 rd person singular subject agreement. ${ }^{29}$ The verbal morphology in these constructions seems to lack a person feature. If we assume V-I raising for EPP satisfaction reasons, the lack of person feature interpretation in the verb agreement morpheme (non- referential verbal features) results in the absence of the nominal feature otherwise necessary to delete the D-feature of the EPP. Similar constructions exist in Italian and Spanish. ${ }^{30}$

This section has shown that EPP on T may not be maintained in its original formulation that subjects occupy SpecTP or that the verb moves to T to satisfy the EPP. EPP is a more general feature than previously assumed and it no longer constitutes the subject requirement. Further crosslinguistic data in the next section reveals: (a) that EPP on T may be satisfied by XPs other than the subject and (b) movement or merge to a projection with an EPP feature may also have information structure effects. ${ }^{31}$

\subsection{EPP and * $(X P)$ Vin Non-V2 Languages}

It has been observed in the literature, admittedly not in a very systematic way, that there exist languages which do not tolerate $V_{1}$ orders. This $V_{1}$ intolerance does not refer to $V_{2}$ Germanic type of languages that consistently require the verb to occur in 2nd position. The relevant theoretical question here is what triggers such intolerance to $V_{1}$. The answer to this question is the topic for a separate study altogether, so we will leave it aside at the moment.

Finnish provides empirical evidence to demonstrate this tendency. Finnish does not seem to tolerate $\mathrm{V}_{1}$ order when the verb displays 3 rd person morphology. As a matter of fact, in these cases, an XP must be situated clause-initially.

29) The peculiarity of these constructions lies on the non-referential nature of the verbs, since it is not possible to think of an entity referred to by a verb like vrehi.

30) Greek, Italian and Spanish do not have any available (c)overt expletives in their system.

31) In recent advances of the Minimalist Program, Chomsky (2002; 2007; 2008) views EPP not as a categorial feature, but instead as a diacritic, as a mark that creates a specifier position. As a result, EPP on I could be dissociated from $D$. 
This observation has led Holmberg and Nikanne (2002) to characterise Finnish as a topic-oriented language:

(30) *sattui minulle onnettomus.

Finnish

happened-3sg to-me accident

'I had an accident.'

According to Holmberg (2005), the ungrammaticality of (30) can be repaired in two ways: either with the fronting of an XP, as in (31), or with the insertion of an expletive, as in $\left(3^{2}\right)$ :

(31) minulle sattui onnettomus.

to-me happened-3sg accident

'I had an accident.'

(32) sitä sattui minulle onnettomus.

expl happened-3sg to-me accident

'I had an accident.'

(Holmberg 2005: 541)

However, this XPV requirement is not only attested in Finnish. Sitaridou (2004) points out that Old French too had an intolerance to $V_{1}$, as demonstrated in (33) and (34):

(33) lors li gita ses braz

after he-dat threw-3sg his arms

'After that, he threw his arms around him'

(Sept Sages 7, 8-9 in Sitaridou 2004: 362)

(34) si commencierent la plus riche navie que onques fist vue si started-3pl the most rich ship that ever was-3sg see-part-fem

'they started (to build up) the most significant ship that was ever seen'

(Clari 22, 1-2 in Sitaridou 2004: 361)

Zubizarreta (1998) makes similar observations for Spanish:

(35) todos los dias compra Juan el diario every the day buys Juan the newspaper

'Juan buys the newspaper every day'

(36) ayer presento Maria su renuncia yesterday handed-in Maria her resignation

'Maria handed-in her resignation yesterday'

(Zubizarreta 1998: 100-101)

Pinto (1997: 22) distinguishes two types of unergatives in Italian; the telefonare type which pattern like unaccusatives and prefer a postverbal subject and the abitare type which require the presence of an overt locative in preverbal position: 
(37) ha telefonato Dante

has called Dante

'Dante called'

(38) in questa casa ha abitato Giacomo Leopardi

in this house has lived/resided Giacomo Leopardi

'Giacomo Leopardi lived in this house'

The same pattern seems to hold true for Greek:

(39) tilefonise o Tianis

called-3sg the-MDA-nom John-nom

'John called'

(40) *(edo) ezise i Maria Kallas

here lived-3sg the-FDA-nom Maria Kallas

'Maria Kallas lived here'32

On the basis of the evidence in which an XP is required clause-initially, Pinto (1997) argues that there is a requirement for a locative argument (LOC) which if not present the sentence is rendered ungrammatical. She also claims that this locative argument has specific information structure effects (i.e. to facilitate focus assignment). Furthermore, Pinto argues that this locative argument satisfies the EPP on T. Therefore, the idea that EPP on T may be satisfied by non-subject elements is not new. Holmberg (2000) explores a similar idea when accounting for Stylistic Fronting in Icelandic. He argues that elements other than subjects occupy the SpecTP for EPP satisfaction. Sitaridou (2004) argues that in Old French the preverbal XP satisfies the EPP. This same XP has discourse effects (i.e. topic continuity reading anchoring previous with current discourse).

All the constructions above seem to regulate the presence of an XP clauseinitially with discourse related effects. This could imply two things: first, that EPP on T may no longer constitute the subject requirement, ${ }^{33}$ explaining why

\footnotetext{
32) Alexiadou (2006) argues that Italian and Greek differ in terms of these constructions, namely that Italian always has an (c)overt LOC filling SpecTP for EPP satisfaction reasons, whereas Greek does not. Her assumption is that pro fills SpecTP in Greek for EPP-satisfaction. In Alexiadou (2000) it was argued that languages like Greek do not project SpecTP. Also, in Alexiadou and Anagnostopoulou (1998) EPP in Greek was satisfied by V-T movement and not by the presence of pro. (40) obligatorily requires a locative on SpecTP (or thereabouts). A detailed discussion on XPV constructions in Greek falls beyond the scope of this paper, but I will be returning to this in future work.

33) Slioussar (2011) argues that in Russian no other XP can satisfy the EPP on T, except a nominative DP.
} 
it may be satisfied by elements other than subjects, and second, that EPP satisfaction may also have an effect on the Interface with regard to the interpretation of information-structure properties. The exact status of the EPP on T and how this gets satisfied fall beyond the scope of this paper.

The empirical evidence above support the new conceptual advances on the EPP. Recent Minimalist developments (see Chomsky 2002; 2007; 2008) entertain the idea that the EPP is a more generalized feature that simply facilitates the operation Merge (Internal and External) and may have discourse related effects at the Interface.

\section{2. $E P P=$ Edge Feature}

There has been a long-standing intuition (cf. Chomsky 2002; 2004) that discourse-related notions such as old/new-information, essentially topics and foci, cannot be related to 'displacement effects' in the narrow syntactic component. This means that pragmatic requirements in any given structure do not implement displacement in the computation. The semantics of these phenomena is attributed to 'language-external' systems such as the S(emantic) $\mathrm{C}$ (omponent). If topics and foci were related to movement operations in the computation, then Syntax would lose its autonomy. ${ }^{34}$

Following Chomsky (2002), we take the pragmatics of old/new information to be semantic properties of expressions that receive an interpretation by the relevant interface systems through the position they occupy in the narrow syntactic component. Properties of an information-structure nature are assigned to the designated lexical elements by the SC on the basis of the position they Merge Internally or Externally.

The question that emerges at this point is how we implement I(nternal) $\mathrm{M}$ (erge) in any given derivation. In Chomsky (2002), IM is not triggered any longer for the satisfaction of uninterpretable agreement features. These can be satisfied in-situ via Agree. EPP is the only feature that triggers IM. Specifically, Chomsky (2002:115) defines EPP as 'here is a position to which you can dislocate' (a position in which an element can be interpreted as dislocated). Effectively, EPP is no longer a subject principle, but a diacritic which triggers IM. As a result, EPP is available not only on $\mathrm{T}$, but also on $\mathrm{C}, \mathrm{v}$, and every other functional projection. In addition, EPP has edge effects, namely the dislocated element may at the Interface receive a topic, focus or specificity reading. Edge effects and edge positions do not necessarily match, that is edge effects are not always assigned in SpecCP and SpecvP (i.e. the edge of strong phases).

\footnotetext{
34) To what extent Syntax is autonomous is a different question altogether.
} 
In recent Minimalist advances, Chomsky (2007; 2008) advocates that there are two types of movement; one is obligatory and involves a Probe-Agree (agreement) feature. The other type of movement is optional and is the result of an EF. Effectively, EF replaces the EPP feature of Chomsky (2002). EF, however, is not an uninterpretable feature which Probes a matching interpretable agreement feature. EF is just an undeletable feature. ${ }^{35}$ Every lexical item has an undeletable EF that allows it to undergo Merge (external or internal). Analogously, every head (lexical or functional) has an EF. EF has been dissociated from the traditional Probe-Agree type of feature because it does not stand for a specific feature (i.e. D, or person, number, etc). It is just an undeletable feature that does not force Merge, but facilitates Merge. Chomsky (2007) assimilates Internal and External Merge with just Merge. In that sense then, EF does not have any real effects in syntax as it remains undeletable there. ${ }^{36} \mathrm{EF}$ can still be related to topic and focus effects just like EPP used to be, however, the movement induced will: (a) have to be optional and (b) will receive interpretation at the interface by the SC. EF does not carry/encode any of these information structural notions, but is just there to permit IM. ${ }^{37}$

The question that immediately arises is how topic and focus receive interpretation by SC in the positions they occupy in Syntax. Sifaki (2003) and Costa and Kula (2008) assume that syntax is 'blind' to topic and focus effects. ${ }^{38} \mathrm{EF}$ facilitates optional movement in syntax, but SC is really relevant for the assignment of Focus. The trigger for movement is an EF and the interpretation lexical elements are assigned comes from systems external to Narrow Syntax at the Interface. I also assume that the focused element of the clause will coincide with the stressed constituent, and as such, Stress will be assigned at the PC. Details of the exact mapping between Syntax, SC and PC remain largely unknown. ${ }^{39}$ In

35) For a distinction between Probe-Agree Features and EF, see Müller (2010).

36) Richards (p.c.) observes that: “Chomsky's reasoning behind this 'undeletability' in his 2007 paper ("Approaching UG from below") is that, if EF were deletable, we would never be able to progress beyond simple head-complement sequences, since first-Merge would already delete the EF. So EF is really just the Merge feature."

37) Müller (2010) argues that a head can have an EF if it has 'an effect on the outcome'. This effect may be an information structure interpretation at the Interface, even though in Müller's examples EF just facilitates intermediate steps of movement in the derivation.

38) In Sifaki (2003) I argued that word order alternations in Greek are viewed as the result of EPP satisfaction. This EPP is available in every functional projection. In this work, EPP is replaced by an EF on the basis of recent Minimalist developments.

39) All non-cartographic approaches are faced with one very difficult task; to explain the interaction of syntax and the semantic and/or phonetic component in the assignment of focus and stress. So far, I have not encountered any account which has managed to formalise this interaction successfully. The only such attempt worth looking at is that of Slioussar (2007), cf. section 5.1.2. Similar difficulties preoccupy researchers of the null subject parameter, specifically how 
section 5.1.2 we explore some of these attempts which try to explain the interaction between Syntax and the Interface and we apply Slioussar's (2007) model to Greek VOS as the most theoretically advantageous.

Before we explore how information structure properties receive an appropriate interpretation at the Interface, we first need to see how VOS is derived syntactically.

\section{Deriving VOS and VadvOS}

As discussed in section 2.1, a typical VOS order in Greek may realise the following focus assignment patterns:

(41) perase tis exetasis I MARIA (oxi i Eleni) passed-3sg the-FDA-acc exams-acc the-FDA-nom Mary-nom (not the Helen)

'Mary passed the exams'

(42) *(telika), PERASE tis exetasis i Maria (finally) passed-3sg the-FDA-acc exams-acc the-FDA-nom Mary-nom

'(In the end) Mary did pass the exams'

(43) perase TIS EXETASIS i Maria passed-3sg the-FDA-acc exams-acc the-FDA-nom Mary-nom

'It was the exams that Mary passed'

Whether the verb, or the object encodes new information, VOS is analysed in a uniform way. More specifically, the verb moves to I to check its agreement features and the object moves to the outer specifier of $\mathrm{vP}$ which possesses an $\mathrm{EF}: 40$

null subjects are retrieved from the discourse. In terms of null subjecthood, most analyses which attempt to outline the interaction between the two components, either involve too many variables (cf. Holmberg 2005; 2010), or have conceptual issues (i.e. feature (un)interpretability in Tsimpli et al. 2004). It would be ideal if the account here could be extended to show the exact interaction between the two components and how the Semantic Component operates to assign focus. For the purposes of this paper, I will follow Slioussar's intuitions, but will return to shed some light on this interaction, to my mind, a necessary step should we envisage syntactocentric accounts to survive time. Tentatively, it might be theoretically advantageous to try and explain the interaction between the two components by appealing to Jackendoff's $(1997 ; 2002)$ model (i.e. components of a grammar operate on a parallel, rather than in a hierarchical fashion, as Chomsky advocates).

40) I do not take Greek VOS to resemble Germanic scrambling/object shift constructions. For a start, the $\mathrm{D}$ (efinineteness) $\mathrm{R}$ (estrictions) effects that hold in object scrambling do not hold true in Greek VOS (cf. Sifaki 2003). 
(44)

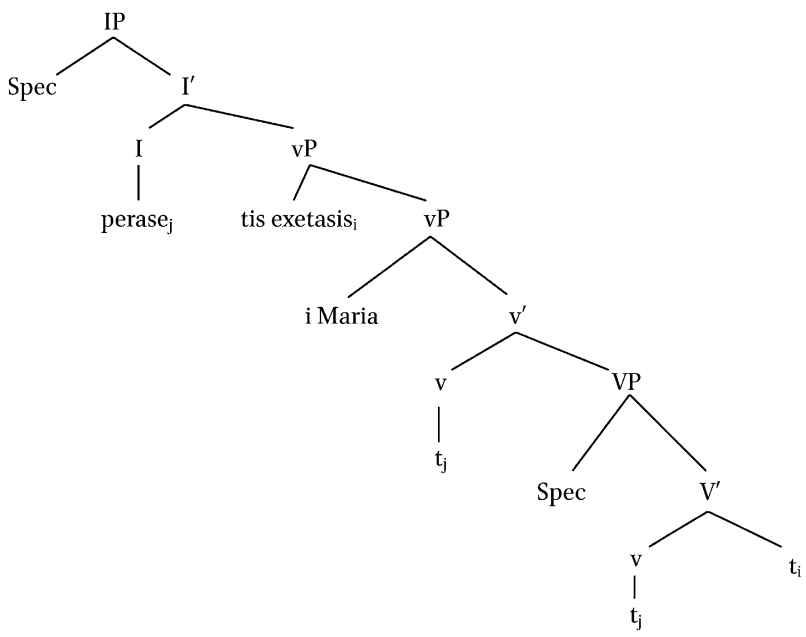

Our system projects multiple specifiers. Chomsky $(2007 ; 2008)$ argues that multiple specifiers come for free provided the EF remains undeleted in Syntax. ${ }^{41}$ Even though there is room for variation here (cf. Müller 2010), the assumption is that normally EM precedes IM. ${ }^{42}$ Therefore, the subject Merges into the inner spec of $\mathrm{vP}$ and the object Merges to the outer spec of vP. This optional movement of the object is triggered by an EF available on the vP. In VOS, it is irrelevant for the syntactic derivation whether focus is received by the verb, or the object. The syntax is blind to information structure properties. As a result, all the focusing patterns attested in VOS are derived through one derivation. ${ }^{43}$ In order to account for VAdvOS we postulate the following derivation:

41) Theoretically, multiple specifiers are freely adopted in any given system. Empirically, they have been motivated to account for Object Shift in which the object moves to a non-thematic SpecvP, and Transitive Expletive Constructions which have been analysed as involving two TP-based specifiers (cf. Chomsky 1995). If movement of the object to the outer SpecvP is A-bar movement, as predicted by the analysis here, then we should encounter WCO effects. The prediction is borne out:

$$
\begin{array}{lllll}
\text { ??ayapai ton } & \text { Kosta } & \text { i } & \text { mama } & \text { tou } \\
\text { loves-3sg } & \text { the-MDA-acc } & \text { Kosta-acc } & \text { the-FDA-nom mother-nom } & \text { of-his } \\
& & &
\end{array}
$$

42) Richards (to appear) argues that as long as there are no tampering effects in the structural relations of the merged objects, then multiple specifiers are free and merging in those should not be severely constrained or ordered.

43) (42) shows that the verb may be assigned new information focus because of an XP located clause-initially. In (44), I will tentatively assume that the XP telika is IP-adjoined. The issue awaits further research on the exact status of these clause-initially located XPs (i.e. temporal, locatives, etc) and their relevance to the information structure properties of the verb. 


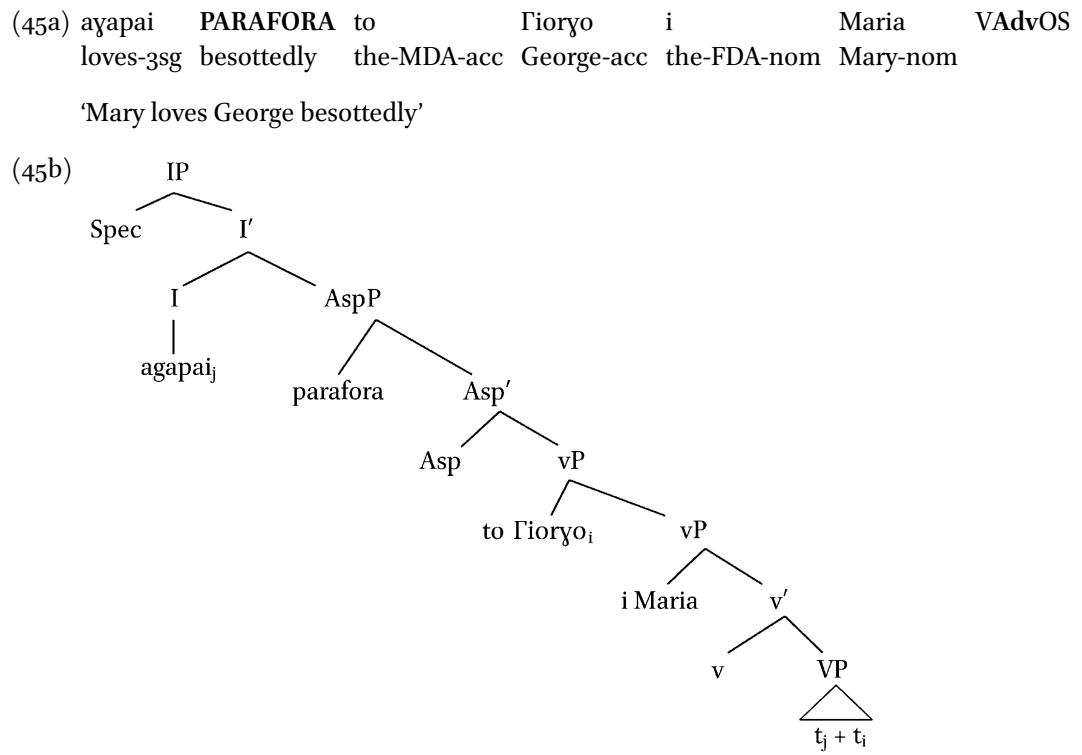

In $(45 \mathrm{~b})$, the adverb merges to the SpecAsp ${ }^{44}$ and receives its focus interpretation by the SC. So, how does SC know which information structure interpretation to assign to each element?

\subsection{Syntax-Information Structure: The Interaction}

The claim here is that Syntax is blind to any information structure/discourse effects. Obligatory IM in the derivation is induced only for agreement features. Everything else that requires optional movement in the derivation moves as a result of an EF which is available in every single head. If elements move optionally for EF reasons, then this movement will need to have interpretive effects at the Interface. As a result of these, we derive Greek VOS and its different focus patterns as instantiating one and only one syntactic derivation. However, if syntax is that blind, then we would anticipate that the Greek derivation would generate the same word order at all times and all things being equal that there would be no interpretive differences between different word orders.

Let us consider some possible theoretical avenues that could explain the mapping between the syntactic derivation of VOS and its different focusing possibilities.

\footnotetext{
44) For information on adverbs located in AspPs in the lower vP area, see Adger and Tsoulas (2000).
} 
5.1.1. Miyagawa (2010)

Miyagawa (2010) dispenses with Topic and Focus Projections in Syntax, yet, he argues for a Probe-Agree topic feature which is simultaneously marked as [-focus]. If this topic feature agrees with a goal that is marked [+focus], then the [-focus] feature of topic becomes [+focus]. He further argues on the basis of data from Japanese that this topic feature is coupled with phi-agreement features. Miyagawa argues that this A-movement for the satisfaction of the agreement feature coupled with a topic feature targets SpecTP as well as some other areas of CP. Even though he does not exclude the fact that this topic feature may also be available on $\mathrm{v}$ and $\mathrm{D}$, he chooses to focus only on the topic feature of $\mathrm{C}$. To my mind, the only difference between previous cartographic accounts and Miyagawa's is that topic/focus movement in his analysis comes alongside phi-agreement, hence why it instantiates A-movement. As for EF, he chooses not to discuss or include it in his analysis. What Miyagawa does is simply dispense with Topic and Focus Projections, but he still permits topic and focus features to operate in the Narrow Syntactic Component. So, an element that moves to satisfy phi-agreement features may simultaneously satisfy a topic or a focus feature.

His account has certain technical weaknesses. For a start, he finds the target of the movement to be only in the left periphery, given that phi-agreement is prevalent and highly operative in most languages there. He does not mention a similar feature operating in the lower IP area, hence he cannot account for crosslinguistic focus patterns. What is more, he assimilates topic and focus as one feature, namely a topic feature which is also marked [-focus]. However, how can a topic feature probe a focus feature and activate the focus feature marking it as [+focus] and [-topic]? I am not convinced that Miyagawa's approach is the right one to take.

Yet, his account has some advantages. I agree with Miyagawa (2010) that if syntax is blind to focus effects, we still need to explain how these are derived. As a result, we will either need to assume that topic and focus are parasitic on agreement features, or that EF is a Probe-Agree feature. The first idea will be subjected to considerable parametrisation, whereas the latter will make the status of EF exactly the same as that of agreement features. ${ }^{45}$ Were we to pursue the second idea and assign to EF the same status as agreement features, then

\footnotetext{
45) Assuming, as the present account does, that EF is not the same as agreement features, it is still essential to demonstrate how the mapping between EF satisfaction and information structure properties (i.e. focus assignment) is achieved. The issue awaits further investigation.
} 
we would need to determine the exact featural value/content for this probeagreement EF. I cannot think of an obligatory EF with content other than that of a topic and/or a focus feature, an undesirable stipulation in the current Minimalist system. A further option to pursue is to assume that some languages will have a purely optional EF that induces movement with topic and focus effects at the interface, whereas others will not. Languages that will have an optional EF will be languages with varying focus possibilities like Greek, whereas languages with obligatorily EFs will be those that encode information structure properties through overt morphemes. Again, this idea requires a plethora of crosslinguistic evidence to define the typology. Slioussar (2007) explores this idea and analyses Russian as involving two types of EFs: those that trigger IM and those that do not.

\subsubsection{Slioussar (2007)}

With evidence from Russian, Slioussar (2007) argues that the EF is what triggers movement in Syntax, but the interpretation is achieved at the Interface. In her account there are two types of EFs; one type does not induce IM, whereas the other does. She assumes that all projections have an EF, but the ones that induce movement in Russian are those on C, T, AdvP, and v. Slioussar (2007) argues that there is a correspondence between Syntax (or else the Computation) and the Conceptual-Intentional system. Furthermore, she identifies two important concepts relevant to information structure (IS); one is saliency and the other is accessibility. Accessibility and saliency are operative in the grammar (in the derivation) and they seem to correspond roughly to the notions of topic and focus, respectively. ${ }^{46}$ To be accurate, saliency and accessibility and focus and topic are not exactly the same thing in Slioussar's model. Her account relates discourse IS to the networks model. The networks model assumes that linguistic units that get to be accessed a lot are more prominent in the mind of the interlocutors. ${ }^{47}$ This networks model is able to identify the information structure properties of linguistic units on the basis of how often these units get accessed in the discourse. The more active a unit is the more accessible it becomes. Based on Lambrecht (1994: 49), Kechagias (2010: 226) argues

46) Kechagias (2010) based on Slioussar (2007) makes similar assumptions to account for VSO and VOS in Greek. His analysis relies on Slioussar's concepts of saliency and accessibility, but movement in his account is not motivated for EF reasons. He also adopts and adapts the notions of thetic and categorical judgments and links these to specific word orders in Greek (for more details, see Kechagias 2010: chapter 6).

47) For similar assumptions in an HPSG framework cf. Engdahl and Vallduvi (1996). 
that saliency and accessibility are 'properties or states of individual referents', whereas topic and focus are relational 'pragmatic notions that link these referents to the proposition'. As put accurately by Kechagias (2010: 226): "Referents thus have a certain IS status, and on the basis of that status they can have a topic or focus relation to the proposition." Depending on the discourse, these IS concepts are variable and may change. Sometimes units are more accessible and other times more salient. Hence, everything is measured on the scale of accessibility and saliency and then these IS properties are mapped into topic and focus interpretations at SC. Since topic and focus are concepts relevant only to the pragmatic component, then they are only part of the SC and not part of syntax. The only relevant properties in syntax are those of the referents measured against the scale of accessibility and saliency. ${ }^{48}$ The scalar effect of saliency and accessibility could be synopsised as below:

If an element $\mathrm{X}$ is more accessible and less salient than $\mathrm{Y}$, and $\mathrm{X}$ is below $\mathrm{Y}$, then instructions are sent over to remerge/or move $\mathrm{X}$ above $\mathrm{Y}$.

The lexical element that is more accessible and less salient pragmatically qualifies as the topic of the discourse (i.e. in the hearer's immediate awareness), whereas the less accessible and more salient element constitutes the focused element. This means that a referent may be more or less accessible and will be the topic or focus in relation to the proposition.

On the basis of empirical evidence and the rule above the assumption is that in Russian the element highest in the tree is the most accessible and least salient, whereas the element lowest in the syntactic domain is the most salient and least accessible. Accessibility and saliency in Slioussar's model are IS values which are updated constantly on the basis of the ever changing discourse.

Assuming that her rule works for Greek VOS too, we would expect that the subject would be the most salient element of all. Nevertheless, this is ruled out by Greek VOS. The subject cannot receive new information focus, but only contrastive focus. Intuitively, this seems to relate to the availability of null subjects in Greek. In order for the subject to be omitted in finite clauses, it must have been previously introduced in the discourse, namely it must constitute old information, or else be the topic of discourse. When the subject is present and focused in VOS, then it is contrasting an individual with some other individual, otherwise it might as well be covert. This is why new information focus

48) As Kechagias (2010: 209) citing Slioussar (2007: 64) puts it: "The PF interface is like a CD player that is designed to convert the information on the disk into music according to a fixed algorithm. Thus, prosodic structures can be part of a very complex conversion process, but essentially, they are derivative, 'read off' from the syntactic structure." 
on the subject in VOS does not sound natural. If the above is true, then the subject needs to be excluded from the saliency and accessibility ranking that Slioussar proposes.

There are two more patterns of focusing evident in VOS; one seems to allow new information focus on the verb only when that is preceded by an XP and the other marks with focus anything that directly follows the verb (i.e. the object or the manner adverb). Even more worth noting is that in the presence of the manner adverb nothing else can be marked with focus except the adverb itself. In effect, saliency in Greek VOS seems to have different directionality than saliency in Russian. Instead of being the lowest element in the tree, the most salient element tends to be the one closest to the edge of the phase.

Contra Slioussar who does not adhere to the notion of phases, we predict that saliency in Greek VOS will mark the highest constituent rather than the lowest in each phase. For instance, when focus falls on the object, this is the highest constituent of the vP phase. When focus falls on the manner adverb this will be the highest element at the edge of the vP phase (assuming that the AspP belongs to the $\mathrm{vP}$ rather than to the $\mathrm{CP}$ phase). The above pattern is also borne out in Greek VSO:
(46) *(telika), EPLINE i Maria ta piata
(finally) washed-3sg the-FDA-nom Mary-nom the-NDA-acc dishes-acc
'(In the end) Mary did wash the dishes'
(47) epline I MARIA (oxi o Tianis) ta piata
washed-3sg the-FDA-nom Mary-nom (not John) the-NDA-acc dishes-acc
'It was Mary who washed the dishes'

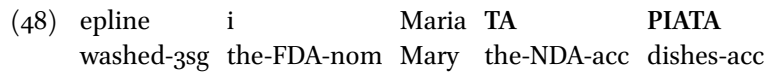
'It was the dishes that Mary washed'
(49) ayapise PARAFORA i Maria to Tiani
loved-3sg besottedly the-FDA-nom Mary-nom the-MDA-acc John-acc
'Mary loved John besottedly'

In (48) the object receives the focus and in the presence of a manner adverb, as in (49), the adverb will be marked with focus. Assuming that the subject is excluded from the accessibility and saliency hierarchy, as in VOS, the most obvious candidates for focus assignment are the object and the manner adverb. Just as in VOS, the verb can be marked with new information focus only when it is preceded by an XP. I will leave this V1 intolerance for future investigation, since it has direct theoretical implications on the status of the EPP on T as hinted at in section 4.1. 


\section{Concluding Remarks}

The present paper argues against the cartographic model in Greek VOS. It is shown that VOS in Greek is derived through one derivation. Movement in this derivation is triggered for agreement features as well as an EF. The assignment of different focus patterns is achieved at the Interface in phases. Adopting assumptions entertained in Slioussar (2007) we assume that the most salient element receives a focus interpretation. However, the directionality of Slioussar's model on saliency and accessibility does not hold true in Greek VOS. In order to account for the Greek data, Slioussar's model was adapted in the following manner:

a. The most salient element in Greek VOS tends to appear to the right of the verb and as a result is the highest constituent in the $\mathrm{vP}$ phase.

b. Since the subject always receives contrastive focus, we assume that this is not included in the accessibility and saliency ranking.

This account has not offered an explanation for the cases in which the verb can receive focus only when preceded by an XP. This XPV structure has further theoretical implications: (a) on the existence and the mode of EPP satisfaction on $\mathrm{T}$, and (b) on the information structure effects induced by this XP. It is also important to return and explain how EF induces information structure effects as well as the exact function of SC and PC in focus and stress assignment. These theoretical questions constitute the topic of another work.

\section{References}

Alexiadou, Artemis. 1999. On the Properties of Some Greek Word Order Patterns. In Artemis Alexiadou, Geoffrey Horrocks, and Melita Stavrou (eds.), Studies in Greek Syntax, 46-55. Dordrecht: Kluwer Academic Publishers.

Alexiadou, Artemis. 2000. Some remarks on Word Order and Information Structure in Romance and Greek. ZAS Working Papers in Linguistics 20: 119-136.

Alexiadou, Artemis. 2006. On the Properties of VSO \& VOS in Greek and Italian. A study on the syntax information structure interface. Proceedings of ISCA. Tutorial \& Research Workshop on Experimental Linguistics $1-8$.

Alexiadou, Artemis and Elena Anagnostopoulou. 1998. Parametrizing Agr: Word Order, V-Movement and EPP-Checking. Natural Language and Linguistic Theory 16: 491-539.

Adger, David and George Tsoulas. 200o. Aspect and Lower VP adverbials. In Artemis Alexiadou and Peter Svenonius (eds.), Adverbs and Adjunction, 1-18. Linguistics in Potsdam.

Belletti, Adriana. 2001. Inversion as Focalization. In Aafke Hulk and Jean Yves Pollock (eds.), Subjects in Romance and the Theory of Universal Grammar, 60-90. New York: Oxford University Press.

Belletti, Adriana. 2004. Aspects of the Low IP Area. In Luigi Rizzi (ed.), The Structure of CP and IP, The Cartography of Syntactic Structures, Volume 2, 16-51. New York: Oxford University Press. 
Brody, Michael. 1990. Some Remarks on the Focus Field in Hungarian. UCL Working Papers in Linguistics 2: 201-225.

Chomsky, Noam. 1995. The Minimalist Program. Cambridge, MA: MIT Press.

Chomsky, Noam. 2002. On Nature and Language. Cambridge: Cambridge University Press.

Chomsky, Noam. 2004. Beyond Explanatory Adequacy. In Adriana Belletti (ed.) Structures and Beyond: The Cartography of Syntactic Structures, Volume 3, 104-131. Oxford: Oxford University Press.

Chomsky, Noam. 2007. Approaching UG from below. In Uli Sauerland and Hans-Martin Gartner (eds.), Interfaces + Recursion = Language ? Chomsky's Minimalism and the View from SyntaxSemantics, 1-30. Berlin: Mouton de Gruyter.

Chomsky, Noam. 2008. On Phases. In Robert Freidin, Carlos P. Otero and Maria Luisa Zubizarreta (eds.), Foundational Issues in Linguistic Theory, 133-166. Cambridge, MA: MIT Press.

Cinque, Guglielmo. 1993. A Null Theory of Phrase and Compound Stress. Linguistic Inquiry 24: 239-298.

Cinque, Guglielmo. 1999. Adverbs and Functional Heads. A Cross-linguistic Perspective. New York: Oxford University Press.

Costa, João. 2004. Subject Positions and Interfaces. Berlin: Mouton de Gruyter.

Costa, João and Nancy C. Kula. 2008. Focus at the Interface: Evidence from Romance and Bantu. In Cécile de Cat and Katherine Demuth (eds.), The Bantu-Romance Connection: A Comparative Investigation of Verbal Agreement, DPs, and Information Structure, 293-322. Amsterdam: John Benjamins.

Engdahl, Elisabet and Enric Vallduví. 1996. Information Packaging in HPSG. In Claire Grover and Enric Vallduví (eds.), Studies in HPSG, Edinburgh: The University of Edinburgh, Edinburgh Working Papers in Cognitive Science, 12: 1-31.

Georgiafentis, Michalis. 2001. On the Properties of the VOS in Greek. Reading Working Papers in Linguistics 5: 137-154.

Georgiafentis, Michalis. 2003. Towards a Phase Based Analysis of the VOS Order in Greek. Reading Working Papers in Linguistics 7: 1-18.

Gryllia, Stella. 2008. On the Nature of Preverbal Focus in Greek. A Theoretical and Experimental Approach. Utrecht: LOT Publications.

Haidou, Konstantina. 200o. Word-order, DP-focusing and the PF Interface: The Case of Modern Greek. SOAS Working Papers in Linguistics 10: 161-192.

Haidou, Konstantina. 2004. On the Syntax-Pragmatics Interface: Left, Medial \& Right-Peripheral Focus and Topic in Greek. Proceedings of the Dislocated Elements Workshop, ZAS Berlin, ZASPiL 35(1) 193-241.

Haidou, Konstantina. 2012. The syntax - pragmatics interface of focus phenomena in Greek. Ph.D. Dissertation, School of Oriental and African Studies.

Hinterhölzl, Roland. 2000. Licensing Movement and Stranding in West Germanic OV languages. In Peter Svenonious (ed.), The Derivation of $\mathrm{VO}$ and $\mathrm{OV}$, 293-327. Amsterdam: John Benjamins.

Hinterhölzl, Roland. 2009. The Role of Information Structure in Word Order Variation and Word Order Change. In Roland Hinterhölzl and Svetlana Petrova (eds.), Information Structure and Language Change. New Approaches to Word Order Variation in Germanic, 45-66. Amsterdam: Mouton de Gruyter.

Holmberg, Anders. 2000. Scandinavian Stylistic Fronting: How Any Category can Become an Expletive. Linguistic Inquiry 31: 445-483.

Holmberg, Anders. 2005. Is There a Little Pro? Evidence from Finnish. Linguistic Inquiry 36: 533564 .

Holmberg, Anders. 2010. Null Subject Parameters. In Theresa Biberauer, Anders Holmberg, Ian Roberts and Michelle Sheehan (eds.), Parametric Variation: Null Subjects in Minimalist Theory, 88-124. Cambridge: Cambridge University Press. 
Holmberg, Anders and Urpo Nikanne. 2002. Expletives, Subjects, and Topics in Finnish. In Peter Svenonius (ed.), Subjects, Expletives, and the EPP, 71-105. Oxford: Oxford University Press. Jackendoff, Ray. 1997. The Architecture of the Language Faculty. Cambridge, MA: MIT Press. Jackendoff, Ray. 2002. Foundations of Language: Brain, Meaning, Grammar, Evolution. Oxford: Oxford University Press.

Kayne, Richard. 1994. The Antisymmetry of Syntax. Cambridge, MA: MIT Press.

Kechagias, Axiotis. 2010. Regulating word order in Modern Greek: Verb initial and non-verb initial orders \& the conceptual-intentional interface. Ph.D. Dissertation, University College London.

Kiss, Katalin. 1998. Identificational Focus versus Information Focus. Language 74(2): 245-273.

Kuroda, Sige-Yuki. 1972. The Categorical and the Thetic Judgment: Evidence from Japanese syntax. Foundations of Language 9: 153-185.

Kotzoglou, George. 2006. Subject Verb Inversion in Greek: Implications for Head Movement and Typology. Journal of Universal Language 7: 91-137.

Lambrecht, Knud. 1994. Information Structure and Sentence Form. Topic, Focus and the Mental Representations of Discourse Referents. Cambridge: Cambridge University Press.

Legate, Julie A. 2003. Some Interface Properties of the Phase. Linguistic Inquiry 34: 506-516.

Miyagawa, Shigeru. 2010. Why Agree? Why Move? Unifying Agreement Based and Discourse Configurational Languages. Cambridge, MA: MIT Press.

Müller, Gereon. 2010. On Deriving CED Effects from the PIC. Linguistic Inquiry 41(1): 35-82.

Ordoñez, Francisco. 1998. Post-Verbal Asymmetries in Spanish. Natural Language \& Linguistic Theory $16(2): 313-346$.

Palmer, Bill. 2009. Clause Order and Information Structure in Cheke Holo. Oceanic Linguistics 48(1): 213-249.

Philippaki-Warburton, Irene. 2001. Гlossoloyiki Aeoria ke Sintaksi tis Elinikis: Pikilia sti Sira ton Oron ke i Erminia tis (Linguistic Theory and the Syntax of Greek: Word Order Variation and its Interpretation). In Proceedings of the 4th International Conference on Greek Linguistics, 217-231. University of Cyprus, September 1999.

Pinto, Manuela. 1997. Licensing and interpretation of inverted subjects in Italian. Ph.D. Dissertation, University of Utrecht.

Puskas, Genoveva. 1992. The Wh-Criterion in Hungarian. Ms., Université de Genève.

Richards, Marc. To appear. Minimalism. In T. Kiss and Artemis Alexiadou (eds.), Syntax: An International Handbook. 2nd edition. Handbook of Linguistics and Communication Science. Berlin/ New York: Mouton de Gruyter.

Rizzi, Luigi. 1982. Issues in Italian Syntax. Dordrecht: Foris.

Rizzi, Luigi. 1997. The Fine Structure of the Left Periphery. In Liliane Haegeman (ed.), Elements of Grammar. A Handbook in Generative Syntax, 281-337. Dordrecht: Kluwer.

Roussou, Anna. 2000. On the Left Periphery. Modal Particles and Complementisers. Journal of Greek Linguistics 1: 65-94.

Roussou, Anna and Ianthi-Maria Tsimpli. 2006. On Greek VSO Again! Journal of Linguistics 42: 317-354.

Sifaki, Evi. 2003. EPP satisfiers; verb-initial orders in Greek. Ph.D. Dissertation, University of York.

Sitaridou, Ioanna. 2004. A Corpus-based Study of Null Subjects in Old French and Occitan. In Claus D. Pusch, Johannes Kabatek, and Wolfang Raible (eds.), Romance Corpus Linguistics II. Corpora and Diachronic Linguistics, 359-374. Tübingen: Gunter Narr Verlag.

Slioussar, Natalia. 2007. Grammar and Information Structure. A Study with Reference to Russian. Utrecht: LOT Publications.

Slioussar, Natalia. 2011. Russian and the EPP Requirement in the Tense Domain. Lingua 121: 20482068.

Spyropoulos, Vasilios and Irene Philippaki-Warburton. 2001. 'Subject' and EPP in Greek: The Discontinuous-Subject Hypothesis. Journal of Greek Linguistics 2: 149-186.

Tsimpli, Ianthi-Maria. 1992. Focusing in Modern Greek. Ms., University College of London. 
Tsimpli, Ianthi-Maria, Antonella Sorace, Caroline Heycock and Francesca Filiaci. 2004. First Language Attrition and Syntactic Subjects: A Study of Greek and Italian Near-native Speakers of English. International Journal of Bilingualism 8(3): 257-277.

Zubizarreta, Maria Luisa. 1998. Prosody, Focus, and Word Order. Cambridge, MA: MIT Press. 